in Human Behavior

Elsevier Editorial system(tm) for Computers

Manuscript Draft

Manuscript Number: CHB-D-16-00356R1

Title: Tell me what they are like and I will tell you where they buy. An analysis of omnichannel consumer behavior

Article Type: Full Length Article

Section/Category: Full Length Article

Keywords: Omnichannel; Impulsiveness; Need for touch; Mobile devices

Corresponding Author: Ms. Paula Rodríguez-Torrico,

Corresponding Author's Institution: University of Burgos

First Author: Paula Rodríguez-Torrico, Ph.D. Student

Order of Authors: Paula Rodríguez-Torrico, Ph.D. Student; Rebeca San José Cabezudo, Ph.D.; Sonia San-Martín, Ph.D.

Abstract: In the past, consumers used to go to brick-and-mortar stores to gather information and often concluded their shopping there, with the physical store probably being one of their few sources of product information. Nowadays, with the arrival of digital devices, the number of sources of information has grown. Consumers tend to combine these with brick-and-mortar establishments both to search and buy, leading to the emergence of omnichannel behavior. In this context, there is a lack of research which considers online and mobile devices separately. The aim of the present study is to analyze how two individual traits -impulsiveness and need for touch- influence the use of each device in the omnichannel decision-making process. Results from a sample of 284 real digital (online and/or mobile) shoppers of clothes confirm that personal traits influence omnichannel consumer behavior. Results show that impulsive shoppers make greater use of mobile devices whereas individuals with high need for touch are more predisposed to use online devices in their omnichannel process. Besides, the effect of individual demographics is taken into account. Finally, we discuss the paper's contributions and outline the actions which managers can engage in so as to succeed in omnichannel retail. 
Tell me what they are like and I will tell you where they buy. An analysis of omnichannel consumer behavior.

Paula Rodríguez-Torrico ${ }^{1}$

Department of Economics and Business Administration, Faculty of Economics and Business, University of Burgos, C/ Parralillos, s/n, 09001 Burgos, Spain. prtorrico@ubu.es

Rebeca San José Cabezudo

Department of Business and Marketing, Faculty of Economics and Business, University of Valladolid, Avda del Valle Esgueva, 6, 47011 Valladolid, Spain.

Sonia San-Martín

Department of Economics and Business Administration, Faculty of Economics and Business, University of Burgos, C/ Parralillos, s/n, 09001 Burgos, Spain.

\footnotetext{
${ }^{1}$ Corresponding author
} 


\title{
Tell me what they are like and I will tell you where they buy. An analysis of omnichannel consumer behavior.
}

\begin{abstract}
In the past, consumers used to go to brick-and-mortar stores to gather information and often concluded their shopping there, with the physical store probably being one of their few sources of product information. Nowadays, with the arrival of digital devices, the number of sources of information has grown. Consumers tend to combine these with brick-and-mortar establishments both to search and buy, leading to the emergence of omnichannel behavior. In this context, there is a lack of research which considers online and mobile devices separately. The aim of the present study is to analyze how two individual traits -impulsiveness and need for touch- influence the use of each device in the omnichannel decision-making process. Results from a sample of 284 real digital (online and/or mobile) shoppers of clothes confirm that personal traits influence omnichannel consumer behavior. Results show that impulsive shoppers make greater use of mobile devices whereas individuals with high need for touch are more predisposed to use online devices in their omnichannel process. Besides, the effect of individual demographics is taken into account. Finally, we discuss the paper's contributions and outline the actions which managers can engage in so as to succeed in omnichannel retail.
\end{abstract}

\section{Introduction}

Omnichannel behavior refers to the use of both physical and digital channels combined with the delivery of seamless shopping experiences (Lazaris \& Vrechopoulos, 2014). Therefore, an omnichannel strategy allows customers to shop across channels anywhere and anytime. In this way, this strategy provides shoppers with a unique, complete, and seamless shopping experience that eliminates the barriers between channels (Juaneda-Ayensa, Mosquera, \& Murillo, 2016). Almost half of all transactions now involve multiple devices (Criteo, 2015). Last year, $49 \%$ of in-store sales in the U.S. were influenced by digital devices (online and mobile) used before or during shopping trips, which involved $\$ 1.7$ trillion (Deloitte, 2015). In this aspect, academic literature has focused mainly on online and offline channel choice for each decision-making stage (Dholakia, Kahn, Reeves, Rindfleisch, Steward, \& Taylor, 2010; Hübner, Wollenburg, \& Holzapfel, 2016; Verhoef, Kannan, \& Inman, 2015). Yet, as technology advances, consumers are using an increasingly wider range of devices such as smartphones and tablets in addition to computers. According to the Interactive Advertising Bureau (IAB, 2015) mobile devices are involved in almost $70 \%$ of buying processes. As the literature has confirmed, channel attributes -digital or otherwise- affect consumers' choice of channel at the various stages of the decision-making process (Gensler, Verhoef, \& Böhm, 2012; Verhoef, Neslin, \& Vroomen, 2007). Therefore, just as online and offline channels have been differentiated, so the same should be done with digital devices, whether they be computers or portable devices (smartphones and tablets, mainly), since these evidence clear differences (screen size, capacity, portability, personality ...) (Gao, Waechter, \& Bai, 2015; Yang \& Kim, 2012). Yet, the research exploring online and mobile channels separately in the omnichannel context remains scarce. Exceptions include Laukkanen's (2007) study in the context of electronic bill paying, which showed that preferences in terms of channel attributes differ between online and mobile consumers. Recently, and in a similar vein, Holmes, Byrne, \& 
Rowley (2014) studied the use of mobile channels in the decision-making process and reported differences in the use of mobile, online and offline channels.

The aim of the present research is thus to gain further insights into omnichannel behavior by analyzing individuals' characteristics, in particular some of the key defining traits of their purchasing behavior: impulsiveness and need for touch (NFT). These traits have been studied in depth in traditional consumer behavior research (Peck \& Childers, 2006; Sharma, Sivakumaran, \& Marshall, 2010), but have received less attention in omnichannel behavior. In their theoretical framework, Dholakia et al. (2010) suggest including consumer traits and features (such as need for touch or need for cognition) when analyzing omnichannel consumer behavior.

In line with previous research, this work considers the two most critical stages of the decisionmaking process -the search and purchase stages- (Elliott, Fu, \& Speck, 2012). Specifically, we focus on the combined use of offline and digital channels. This paper fills two gaps; first, while most research explores omnichannel processes taking into account offline and online channels (PC/laptop), the present research also includes the mobile channel (smartphone/tablet). Secondly, this work analyzes how personal variables -which are determinants of consumer behavior- influence the way consumers engage in omnichannel processes depending on each channel.

\section{Theoretical background and research hypotheses}

\subsection{Impulse and contemplative behavior: impulsiveness vs. need for touch}

Two of the purchase behaviors to have aroused most interest among researchers are impulsive and contemplative behavior (Rook, 1987), highlighting the need to study two consumer traits: impulsiveness vs. need for touch. Impulse behavior occurs when "a consumer experiences a sudden, often powerful and persistent urge to buy something immediately" (Rook, 1987, p. 191). Conversely, contemplative behavior is defined as "a buying action undertaken with a problem having been previously recognized" (Piron, 1993). Impulse buying is a sudden and high-speed experience, whereas contemplative purchases are not made with such haste but are conducted slowly. Impulsive purchasing is more spontaneous and tends to stem the flow of consumer behavior. In contrast, contemplative behavior is more cautious and often forms part of a shopping routine (Rook, 1987; Weinberg \& Gottwald 1982). Impulsive buying is characterized by high levels of emotional activation and low levels of cognitive control (Arnould, Price, \& Zinkhan 2002) whereas contemplative buying is a more deliberate and controlled cognitive process (Morrin \& Chebat, 2005).

Engaging in either impulsive/contemplative behavior also depends on consumer personality (Weinberg \& Gottwald, 1982). It has been demonstrated that impulsive shoppers differ from contemplative shoppers in personality. Impulsive shoppers think more about the short-term benefits or pleasures that result from impulsive buying behavior. Conversely, contemplative buyers pay more attention to the long term costs of impulsive behavior, and thus undertake a more thoughtful evaluation process (Puri, 1996).

Impulsiveness is defined as the degree to which an individual is likely to make unintended, immediate, and unreflective purchases (Weun, Jones, \& Beatty, 1998, p. 1124). Based on this 
definition, impulsiveness is related to impulse behavior. High impulsiveness individuals are thus more likely to engage in such behavior (Puri, 1996). In the literature, impulsiveness -as a personal trait- has been considered a determinant of impulse behavior (Beatty \& Ferrell, 1998; Puri, 1996; Rook \& Fisher 1995; Stilley, Inman, \& Wakefield, 2010). Research has also noted that impulse buying is characterized by the impulsiveness with which a consumer acts. For example, Adelaar, Chang, Lancendorfer, Lee, \& Morimoto (2003) confirmed that people who tend to be impulsive have a greater susceptibility to purchase items on impulse.

Need for touch (NFT) is defined as "a preference for the extraction and utilization of information obtained through the haptic system" (Peck \& Childers, 2003a, p.431). NFT is a multidimensional construct with two factors, instrumental and autotelic. The autotelic dimension is related to touch as an end in and of itself. As in other studies (Peck \& Childers, 2006; Peck \& Wiggins, 2006), the present research will consider only one NFT factor, in this case the instrumental factor. Instrumental NFT relates to an outcome-directed touch with a salient purchase goal. That is, consumers make contact with the product in order to gather information, seeking a solution to their purchase problem (Peck \& Childers, 2003a). These high NFT shoppers will engage in contemplative behavior, which is characterized as a cognitive and prudent process (Puri, 1996).

\subsection{Research hypotheses}

Recent studies have indicated that impulse purchases can implicate various degrees of prepurchase planning, and not only entail unplanned shopping (Workman, 2010). Although impulse behavior is preceded by a consumer's intent to buy impetuously, environment cues such as the channel can enhance acting on impulse (Adelaar et al., 2003; Drossos, Kokkinaki, Giaglis, \& Fouskas, 2014). The very nature of mobile devices can create in consumers an urge to buy impulsively. Mobile device proximity and immediacy makes the consumer more vulnerable to impulse buying (Watson, Pitt, Berthon, \& Zinkhan, 2002). Furthermore, mobile shopping's quick responsiveness and convenience makes consumers more impulsive (Lee, Park, \& Jun, 2014). It has also been evidenced that impulsiveness is related with a greater use of mobile services (Drennan \& Sullivan Mort, 2003). Mobile devices thus stimulate impulse behavior since mobile users can search and purchase products and services in an easy and immediate way. Therefore,

\section{H1: Omnichannel processes through the mobile channel will be carried out more frequently by high impulsive consumers than by low impulsive consumers.}

Furthermore, online omnichannel shoppers may tend to implement contemplative behaviors. This contemplative behavior is engaged in by individuals with high NFT who chronically access haptic information at the evaluation stage (Peck \& Childers, 2003a). Higher NFT individuals are more confident in their judgments when they can touch the product (Peck \& Childers, 2003b), and this level of high NFT consumer self-confidence is increased after touching a product previously considered in the online environment (Gurrea \& Orús, 2014). Therefore, high NFT individuals also touch the product, thereby evaluating it two-fold and in order to be sure about their judgments and to confirm the value or quality of the product in question (Peck \& Childers, 2003a). In this line, Konus, Verhoef, \& Neslin (2008) found that online multichannel shoppers use both online and offline channels in their decision-making process in order to 
explore and find the best option, and that they are more innovative and price-conscious. In addition, the online channel is used for mainly planned purchases and when consumers have a specific purchase in mind (Wolfinbarger \& Gilly, 2001). So,

H2: Omnichannel processes through the online channel will be carried out more frequently by high NFT consumers than by low NFT consumers.

Although individuals may be expected to develop omnichannel processes through both the online and mobile channel, frequency of use of mobile devices versus online devices is also expected to be greater for high impulse individuals. Besides the nature of mobile devices -they are ubiquitous and consumers carry them everywhere and at all times-, mobile marketing actions are designed to encourage impulse purchases (San-Martín \& López-Catalán, 2013). In this line, Rook (1987) noted that these promotional incentives can stimulate the impulsive urge to buy. Impulse shopping behavior is also stimulus driven and impulsive consumers are expected to respond positively and immediately to this stimuli (Rook \& Fisher, 1995). Consequently, these stimuli increase the sense of urgency and, as a result, this channel will attract impulsive individuals. So,

H3: Frequency of channel use (mobile vs. online) in omnichannel processes is greater for high impulsiveness than for low impulsiveness.

The online channel provides greater access to information in addition to which online device features (bigger screens, higher capacity to show more information and more details, faster connection) allow this to be shown better than mobile devices can hope to do. Together with page and content design, these features are some of the key determinants of online commerce success (Ozok \& Wei, 2010). The bigger interface offered by online devices often makes transactions simpler and easier (Strader \& Inapudi, 2004). Mobile devices are frequently too small to view all of the necessary information (Gao et al., 2015) and to make a contemplative evaluation and decision. In addition, consumers feel the online channel offers access to more information and the computer interface enables information to be valued more easily (Strader \& Inapudi, 2004). Knowing that instrumental information for individuals with high NFT is crucial to increase confidence in their judgment and reduce frustration (Peck \& Childers, 2003b), online devices will adapt better than mobile devices to perform the evaluation and decision process. Consequently, these devices will be used more than mobile devices by consumers who need more time and more information to make their decision.

H4: Frequency of channel use (online vs. mobile) in omnichannel processes is higher for high NFT than low NFT.bbh

\section{Method}

\subsection{Data collection}

This empirical study is based on information collected from digital shoppers of a Spanish clothing company. These digital shoppers are consumers who have purchased clothes through online and/or mobile channels. The company contacted 1,649 customers via email and provided them with the link to the online questionnaire. The company selected only clients who had purchased in the online or mobile store. The email reached 1,612 customers of whom $655(40.63 \%)$ opened it. These buyers had access to the questionnaire for 15 days in June 
2014. Respondents were first asked about variables related to their personality. They then answered questions about their omnichannel behavior. To encourage them to take part, respondents were informed that after completing the survey they would be given a $5 €$ coupon for their next purchase in the company. In order to prevent subjects completing the survey more than once, clients could only enter the coupon code from any given IP address once. The final useful sample amounted to 284 individuals. The sample was made up almost entirely of women (98.6\%); aged 19-35 (33.3\%), 36-50 (64.2\%), and over 50 (2.4\%) who were mainly in employment (85.6\%).

\subsection{Industry selection}

The clothing industry was chosen because several reasons. First, it is one of the fastest growing sectors in digital purchases. In addition, apparel is in the top ten most influenced categories by digital devices when shopping in stores (Deloitte, 2016), added to which it has been one of the main topics addressed in the literature (Evans, 1989; Kim, Jin Ma \& Park, 2009). Finally, as an experiential product, clothes require sensitive input for evaluation. This can imply the use of digital channels combined with brick-and-mortar in the decision-making process, such that omnichannel analysis proves more important.

\subsection{Measurement}

The questionnaire for this study was developed from reliable and valid scales taken from previous literature. All items were measured through 5-point Likert scales, ranging from strongly disagree (1) to strongly agree (5). First the questionnaire comprised personality variables -impulsiveness and NFT-. To measure impulsiveness, three items were adapted from Brashear, Kashyap, Musante \& Donthu (2009) and four items of the instrumental need for touch scale were taken from Peck \& Childers (2003a). The second part comprised omnichannel questions. In this case, individuals were asked how often they engaged in online omnichannel processes: (a) searching offline and purchasing online; (b) searching online and purchasing offline; and mobile omnichannel processes: (a) searching offline and purchasing mobile; and (b) searching mobile and purchasing offline. In order to develop online and mobile omnichannel frequency, we calculated the arithmetical average between both online and mobile items.

\section{Results}

\subsection{Validation and data analysis}

Confirmatory factor analysis (CFA) was performed using Smart PLS to evaluate the psychometric properties of the impulsiveness and NFT scales in terms of reliability, convergent validity and discriminant validity (see Table 1 ). Reliability was confirmed through composite reliability (CR) and Cronbach alpha. CR exceeded 0.7 for all factors, and Cronbach alpha values were above 0.7 , suggesting good reliability. Average variance extracted (AVE) was greater than 0.5 for all variables, which meant that over $50 \%$ of the variances observed in the items were accounted for by their factors. In addition, all item loadings were significant and above 0.7, thus confirming convergent validity (Bagozzi \& Yi, 1988). Discriminant validity was also confirmed, as the square root of the AVE in all cases was higher than the correlation between 
variables (Fornell \& Larcker, 1981). In summary, measurement instruments display acceptable reliability and validity.

\section{TABLE 1}

\subsection{Online vs. mobile channel use}

Before testing the research hypotheses, we wanted to confirm whether online and mobile channels differ from each other. To that end, we first analyzed each channel's frequency of use at the various stages of the decision-making process. Table 2 shows the prominence of the online channel in most decision-making process stages. Focusing on the mobile channel, it can be seen how the latter is more important in the early stages, such as when searching for information and weighing up alternatives, than in the latter stages related to buying and payment, thus confirming Holmes et al's. (2014) findings.

\section{TABLE 2}

Second, we also studied the frequency of online and mobile omnichannel processes (Table 3). As can be seen, the online channel is still used more often than the mobile channel. Results confirm the different use of online and mobile channels in omnichannel behavior; mobile channel use still proving infrequent, with online channels being used most commonly for this process.

\section{TABLE 3}

\subsection{Personal traits in omnichannel behavior}

As frequency of online use is higher than mobile use, we created a variable to compare online and mobile channel frequency of use. This variable, which we call frequency of channel use, is the difference between online and mobile omnichannel frequencies. High values of this variable indicate more online relative use whilst low values indicate more mobile relative use.

To test our research hypotheses, univariate analysis of variance (ANOVA) and multiple linear regression analysis were conducted using SPSS Statistics 23. To prepare for the ANOVA analyses, participants were categorized into two groups, high and low, for each variable impulsiveness and NFT-. Using the scales included in Table 1, we saved the corresponding belonging factor and we used that value to divide the sample into two groups, for each of the variables considered in this study: those who show high (above the average value) and low (below the average value) impulsiveness and those who exhibit high and low NFT, respectively. Additionally, we performed a t-test of mean difference and it shows that, effectively, the means of values of impulsiveness and NFT, in the ad hoc created groups, are significantly different. On the one hand, the mean value of high impulsive individuals is $4.246(n=132)$ and of low impulsive individuals is $2.386(n=152)(t=-28.314 ; p<0.001)$. On the other hand, high NFT individuals show a mean value of $3.817(n=141)$, which is significantly different from the mean value of the low NFT individuals $(1.986)(n=143)(t=-27.436 ; p<0.001)$. These results show that the means are above and below the average value ( 3 points) of the 5 -point Likert scales. Therefore, all the previous reasoning allows us to test the effect of both factors on the dependent variables of this research. 
Table 4 depicts mobile omnichannel behavior, with results showing that in this omnichannel process, high impulsiveness individuals tend to use mobile devices more frequently ( $M=1.947$, $S D=1.069)$ than individuals with low impulsiveness $(M=1.609, S D=0.796)(F=8.875 ; p$ $<0.05$ ), thus confirming $\mathrm{H} 1$. As a result, greater impulsiveness implies a higher use of mobile devices in an omnichannel context.

\section{TABLE 4}

In addition, as can be seen in Table 5 , the online channel is used more frequently by high NFT than by low NFT consumers ( $M=2.484, S D=0.775$ versus $M=2.085, S D=0.807)(F=17.097, p$ $<0.05)$, thus supporting $\mathrm{H} 2$. Accordingly, when consumers display a greater NFT, they use online devices more in their omnichannel behavior than do people who evidence less NFT.

\section{TABLE 5}

Although $\mathrm{H} 1$ and $\mathrm{H} 2$ have already been supported, there are studies that suggest some sort of relationship between demographics and frequency of use of digital devices (Alkhunaizan \& Love, 2013; Chong, 2013; Pearce \& Rice, 2013). In order to examine the effect of demographics on mobile and online omnichannel frequency of use, two analysis of covariance (ANCOVA) were conducted. For both analyses the independent and dependent variables (factor) were maintained and age and occupation were included as covariates. Results show that age influences the frequency of use of mobile devices in omnichannel processes, however no significant impact of the frequency of use of online channel was found on those omnichannel processes. In addition, occupation does not show any significant influence on mobile and online frequency of use. Finally, in both cases, significant impact of high and low impulsiveness on frequency of use and of high and low NFT on frequency of use in omnichannel processes are found, providing increased support to $\mathrm{H} 1$ and $\mathrm{H} 2$.

To see the differences in the impact of high impulsive/NFT and low impulsive/NFT individuals on frequency of channel use, an ANOVA analysis was performed (Table 6). Results show that mobile frequency of use in relation to online frequency of use is higher for impulsive consumers in omnichannel processes $(M=0.425$ versus $M=0.576)(F=5.621, p<0.05)$, therefore supporting H3. Furthermore, compared to low NFT individuals ( $M=0.353$ ), high NFT individuals use the online channel more) than the mobile channel in their omnichannel processes $(M=0.648)(F=21.35, p<0.05$. Thus, $H 4$ is also confirmed, NFT implies the use of online devices more than the use of mobile devices. As can be seen in Table 6, the interaction between impulsiveness and NFT is not significant.

\section{TABLE 6}

Finally, a multiple linear regression model was estimated, including impulsiveness and NFT as independent variables and age as a control variable. Results show the significant influence of all the variables on the frequency of channel use (Table 7). Firstly, impulsiveness has an indirect impact on the dependent variable, which implies, as it was posited, more frequency of use of mobile channel in relation to online channel. Secondly, NFT shows a significant and positive influence on frequency of use, which means that NFT consumers prefer online versus mobile channel to carry out their omnichannel processes. 
TABLE 7

\section{Discussion and implications}

Today, consumers have added digital (online and mobile) devices to their purchase decision process. The present work thus seeks to explore how the behavior pattern differs when engaging in the omnichannel process via online devices compared to through mobile devices, also taking into account individuals' personality traits.

With information gathered from 284 real clothing online and/or mobile shoppers, we evidence through ANOVAS and a multiple linear regression model the difference between behavior in the online and mobile channel, confirming and expanding the findings to emerge from previous work (Holmes et al., 2014). More specifically, our results contribute to academic literature in two ways. On the one hand, personality traits determine the frequency of omnichannel behavior with each device. On the other hand, said variables also determine channel preference, concretely impulsiveness implies mobile preference and NFT online preference in omnichannel processes. This leads us to conclude that consumers use the device that is best suited to their behavior.

\subsection{Mobile omnichannel behavior}

Results confirm that the mobile omnichannel process is most often engaged in by impulsive as opposed to non-impulsive individuals. In addition, these impulsive individuals use relatively more mobile devices compared to online devices than do low impulsive individuals. These results may indicate that impulse consumers perceive that mobile devices suit their urgent needs better. The nature of mobile devices, their size and physical characteristics, allow consumers to search and shop anywhere and at any time (Gao et al., 2015; Wang, Malthouse, \& Krishnamurthi, 2015). Furthermore, consumer-oriented mobile marketing action is often designed to encourage consumers to make spur-of-moment purchases. Our results confirm that mobile devices can "calm" the urgent need to seek information or to buy which highimpulse consumers feel. Therefore, an increasingly widespread consumer practice is for them to use their mobile devices in physical stores (Rapp, Baker, Bachrach, Ogilvie, \& Beitelspacher, 2015). One possible scenario is that individuals are in the physical store with their mobile device and, thanks to its ubiquity, can use it to find out information about the product before then completing their in-store purchase. Alternatively, they may analyze the product at the actual store and then use the mobile device to secure some of the specific benefits offered by mobile shopping when making the final purchase (Rapp et al., 2015).

\subsection{Online omnichannel behavior}

Furthermore, high NFT individuals are more likely to engage in omnichannel processes through the online channel than are low NFT consumers. In addition, as the regression model estimation confirmed, they still prefer to use their computers as opposed to new mobile devices in such cases. These consumers are characterized by being evaluative and contemplative when making their purchasing decisions. Online devices allow them to consult more detailed information than mobile devices due to their physical characteristics: larger screens, better image resolution, and greater ability to display information and, generally, with better internet connection (Strader \& Inapudi, 2004). In addition, the computer is often used 
at home and for longer periods, unlike mobile devices, which are used at isolated micromoments or when people are on "standby" (Harvard Business Review, 2015). Therefore, online omnichannel processes are characterized as being longer and more contemplative. In this case, two scenarios are possible. First, consumers use their computers to find information about the product and then go to the physical store to confirm their online judgments, touching the product before purchase. Conversely, this contemplative buyer may go to the physical store to examine and evaluate the product, after which physical examination, they purchase through their computer, conscious of the advantages of the online channel (better prices, discounts...) (Elliott et al., 2012; IAB, 2015).

\subsection{Management implications}

Consumers use many channels simultaneously during all phases of the making-decision process. The separation between physical and digital channels makes no sense since consumers access them interchangeably and expect to find the same products, services, conditions and attention. Given such a situation, companies should create an omnichannel strategy for an omnichannel consumer (Lazaris \& Vrechopoulos, 2014). In order to develop a good strategy, companies must first identify the consumer whose needs and wishes are to be satisfied. In addition, the results of this study indicate that omnichannel individuals display different features such that each strategy must adapt to the demands of each channel, these being determined by what consumers expect to find on that channel and how they use it, which is in turn a consequence of their personality.

Mobile omnichannel individuals are more impulsive and so demand a faster purchasing process. To do this, companies must allow consumers to complete their shopping quickly and easily. Consequently, the design of mobile webs and apps should be simple, clear and should involve few steps to checkout and few pages to navigate. These websites must have high usability and display products in an appropriate size and with the required image quality. They should show only the most important and necessary information and it is also important to use attractive calls to action that entice the user to perform the desired behavior. For personal information, companies must coordinate offline and online channel information with the mobile so that buyers do not need to register their information and can thus be identified quickly (for example, one-click ordering from Amazon) and subscribe to information "alerts" that can lead to immediate behavior (for example, the case of alerts for sales offers). Similarly, it is important for companies to be transparent in this context by clarifying and providing access to the conditions, guarantees as well as security and privacy policies and, of course, by providing a good service since, as has been confirmed in previous studies, impulse buying can generate negative experiences (Rook, 1987). One aspect that could make the difference between companies in the sector is to provide Wi-Fi in the physical store. Since, in many cases, the mobile device is being used for in-store purchases, this will improve the integration of channels as well as allow actual customer behavior to be tracked.

As for the online channel, results indicate that these processes are more contemplative and entail additional time. Individuals need to confirm their judgments by touching, either before or after making the decision. In this situation, companies must facilitate traffic between the online and the physical store by making the same offers, conditions and services available on both channels. Similarly, websites must be designed so as to include written instrumental 
haptic information, since this makes up for the inability to evaluate products through touch, thereby increasing confidence in judgments and reducing the potential frustration of high NFT consumers (Overmars \& Poels, 2015; Peck \& Childers, 2003b). For example, descriptions should include information regarding the touch characteristic of the products such as materials or texture. Likewise, product images should offer high resolution that can display product composition easily with zooms or several pictures. Moreover, adequate return guarantee policies for products must be available if there is dissatisfaction after physical touch and try.

\section{Limitations and further research}

As for the limitations of the research, omnichannel processes have been considered as the combination of a digital channel and the physical store. Combinations of digital channels together with the use of more than two channels in the same process have not been taken into account. Future research could be extended by including the combined use of online, mobile and offline channels in the same process, since consumers can use more than two channels in the same process, and can even use more than one channel for the same stage of the process. Additionally, frequency of channel use has been calculated with a variable that shows the relative use of each channel. Since the frequency of mobile channel use remains low it has not been possible to compare preferences in absolute terms.

In addition, this work has only considered individuals' internal aspects. Elsewhere, future work might also explore the influence of new contextual variables such as the characteristics of each channel. In this sense, it would be interesting to get deeper into the effects of demographics on shopping channel preferences. The results of this study show some significant effects of age, concretely on mobile preference. On the contrary, occupation does not show any significant effects on omnichannel processes and it should be further studied in another research. However, we have not been able to test the effect of other variables such as gender due to the sample used, which was almost entirely composed by women, but in future research gender differences can be proposed.

Finally, it would be interesting to replicate the results of our study using another product category or industry.

\section{References}

Aaker J. (1999). The malleable self: The role of self-expression in persuasion. Journal of Marketing Research, 16, 45-57.

Adelaar, T., Chang, S., Lancendorfer, K. M., Lee, B., \& Morimoto, M. (2003). Effects of media formats on emotions and impulse buying intent. Journal of Information Technology, 18(4), 247266.

Alkhunaizan, A., \& Love, S. (2013). Effect of demography on mobile commerce frequency of actual use in Saudi Arabia. In Advances in information systems and technologies (pp. 125-131). Berlin Heidelberg: Springer.

Arnould, E. J., Price, L., \& Zinkhan, G. M. (2002). Consumers. McGraw-Hill/Irwin. 
Bagozzi, R. P., \& Yi, Y. (1988). On the evaluation of structural equation models. Journal of the academy of marketing science, 16(1), 74-94.

Beatty, S. E., \& Ferrell, M. E. (1998). Impulse buying: modeling its precursors.Journal of retailing, 74(2), 169-191.

Brashear, T. G., Kashyap, V., Musante, M. D., \& Donthu, N. (2009). A profile of the Internet shopper: Evidence from six countries. Journal of Marketing Theory and Practice, 17(3), 267282.

Chong, A. Y. L. (2013). Mobile commerce usage activities: The roles of demographic and motivation variables. Technological Forecasting and Social Change, 80(7), 1350-1359.

Criteo. State of mobile commerce. Cross-device shopping starts and ends on mobile Q3 2015. (2015). http://www.criteo.com/media/3099/criteo-state-of-mobile-commerce-q3-2015-es.pdf Accessed 26.11.2015.

Deloitte. Navigating the new digital divide. A global summary of findings from nine countries on digital influence in retail. (2016). http://www2.deloitte.com/global/en/pages/consumerbusiness/articles/gx-global-digital-divide-retail.html. Accessed 4.11.2016

Dholakia, U. M., Kahn, B. E., Reeves, R., Rindfleisch, A., Stewart, D., \& Taylor, E. (2010). Consumer behavior in a multichannel, multimedia retailing environment. Journal of Interactive Marketing, 24(2), 86-95.

Drennan, J. C., \& Sullivan Mort, G. (2003). Examination of the influence of personal attributes on consumer use of m-services. In ANZMAC conference (pp. 809-817). The University of South Australia.

Drossos, D. A., Kokkinaki, F., Giaglis, G. M., \& Fouskas, K. G. (2014). The effects of product involvement and impulse buying on purchase intentions in mobile text advertising. Electronic Commerce Research and Applications, 13(6), 423-430.

Elliott, M. T., Fu, F. Q., \& Speck, P. S. (2012). Information search and purchase patterns in a multichannel service industry. Services Marketing Quarterly, 33(4), 292-310.

Evans, M. (1989). Consumer behaviour towards fashion. European Journal of Marketing, 23(7), 7-16.

Fornell, C., \& Larcker, D. F. (1981). Evaluating structural equation models with unobservable variables and measurement error. Journal of marketing research, 18(1), 39-50.

Gao, L., Waechter, K. A., \& Bai, X. (2015). Understanding consumers' continuance intention towards mobile purchase: A theoretical framework and empirical study-A case of China. Computers in Human Behavior, 53, 249-262.

Gensler, S., Verhoef, P. C., \& Böhm, M. (2012). Understanding consumers' multichannel choices across the different stages of the buying process. Marketing Letters, 23(4), 987-1003. 
Gurrea, R., \& Orus Sanclemente, C. (2014). El papel de la vivacidad de la información online, la necesidad de tocar y la auto-confianza en la búsqueda de información online-offline. Revista Española de Investigación en Marketing ESIC, 18(2), 108-125.

Harvard Business Review. (2015). Micro-moments and the shopper journey. A Harvard Business Review analytic services report 2015.

Holmes, A., Byrne, A., \& Rowley, J. (2013). Mobile shopping behaviour: insights into attitudes, shopping process involvement and location.International Journal of Retail \& Distribution Management, 42(1), 25-39.

Hübner, A., Wollenburg, J., \& Holzapfel, A. (2016). Retail logistics in the transition from multichannel to omni-channel. International Journal of Physical Distribution \& Logistics Management, 46(6/7).

Interactive Advertising Bureau. Estudio mobile. (2015). http://www.iabspain.net/wpcontent/uploads/downloads/2015/09/Estudio-Mobile-2015.pdf Accessed 10.11.2015

Juaneda-Ayensa, E., Mosquera, A., \& Murillo, Y. S. (2016). Omnichannel Customer Behavior: Key Drivers of Technology Acceptance and Use and Their Effects on Purchase Intention. Frontiers in Psychology, 7(Article 1117).

Kim, J., Jin Ma, Y., \& Park, J. (2009). Are US consumers ready to adopt mobile technology for fashion goods? An integrated theoretical approach. Journal of Fashion Marketing and Management: An International Journal, 13(2), 215-230.

Konuş, U., Verhoef, P. C., \& Neslin, S. A. (2008). Multichannel shopper segments and their covariates. Journal of Retailing, 84(4), 398-413.

Laukkanen, T. (2007). Customer preferred channel attributes in multi-channel electronic banking. International Journal of Retail \& Distribution Management, 35(5), 393-412.

Lazaris, C., \& Vrechopoulos, A. (2014, June). From multi-channel to "omnichannel" retailing: review of the literature and calls for research. In 2nd International Conference on Contemporary Marketing Issues (ICCMI).

Lee, T., Park, C., \& Jun, J. (2014). Two Faces of Mobile Shopping: Self-Efficacy and Impulsivity. International Journal of E-Business Research (IJEBR), 10(1), 15-32.

Morrin, M., \& Chebat, J. C. (2005). Person-place congruency the interactive effects of shopper style and atmospherics on consumer expenditures. Journal of Service Research, 8(2), 181-191.

Ozok, A. A., \& Wei, J. (2010). An empirical comparison of consumer usability preferences in online shopping using stationary and mobile devices: results from a college student population. Electronic Commerce Research, 10(2), 111-137.

Overmars, S., \& Poels, K. (2015). Online product experiences: The effect of simulating stroking gestures on product understanding and the critical role of user control. Computers in Human Behavior, 51, 272-284. 
Pearce, K. E., \& Rice, R. E. (2013). Digital divides from access to activities: Comparing mobile and personal computer Internet users. Journal of Communication, 63(4), 721-744.

Peck, J., \& Childers, T. L. (2006). If I touch it I have to have it: Individual and environmental influences on impulse purchasing. Journal of business research, 59(6), 765-769.

Peck, J., \& Childers, T. L. (2003a). Individual differences in haptic information processing: The "need for touch" scale. Journal of Consumer Research, 30(3), 430-442.

Peck, J., \& Childers, T. L. (2003b). To have and to hold: The influence of haptic information on product judgments. Journal of Marketing, 67(2), 35-48.

Peck, J., \& Wiggins, J. (2006). It just feels good: Customers' affective response to touch and its influence on persuasion. Journal of Marketing, 70(4), 56-69.

Piron, F. (1993). A comparison of emotional reactions experienced by planned, unplanned and impulse purchasers. Advances in Consumer Research, 20(1), 341-344.

Puri, R. (1996). Measuring and modifying consumer impulsiveness: A cost-benefit accessibility framework. Journal of consumer Psychology, 5(2), 87-113.

Rapp, A., Baker, T. L., Bachrach, D. G., Ogilvie, J., \& Beitelspacher, L. S. (2015). Perceived customer showrooming behavior and the effect on retail salesperson self-efficacy and performance. Journal of Retailing, 91(2), 358-369.

Rook, D. W., \& Fisher, R. J. (1995). Normative influences on impulsive buying behavior. Journal of consumer research, 22(3), 305-313.

Rook, D. W. (1987). The buying impulse. Journal of consumer research, 14(2), 189-199.

San-Martin, S., \& López-Catalán, B. (2013). How can a mobile vendor get satisfied customers? Industrial Management \& Data Systems, 113(2), 156-170.

Sharma, P., Sivakumaran, B., \& Marshall, R. (2010). Impulse buying and variety seeking: A traitcorrelates perspective. Journal of Business Research, 63(3), 276-283.

Stilley, K. M., Inman, J. J., \& Wakefield, K. L. (2010). Planning to make unplanned purchases? The role of in-store slack in budget deviation. Journal of Consumer Research, 37(2), 264-278.

Strader, T. J., \& Inapudi, A. (2004). User perceptions of mobile and online channels for purchasing financial products. Journal of Internet commerce, 3(1), 91-101.

Verhoef, P. C., Kannan, P. K., \& Inman, J. J. (2015). From multi-channel retailing to omnichannel retailing: Introduction to the special issue on multi-channel retailing. Journal of Retailing, 91(2), 174-181.

Verhoef, P. C., Neslin, S. A., \& Vroomen, B. (2007). Multichannel customer management: Understanding the research-shopper phenomenon. International Journal of Research in Marketing, 24(2), 129-148. 
Wang, R. J. H., Malthouse, E. C., \& Krishnamurthi, L. (2015). On the go: how mobile shopping affects customer purchase behavior. Journal of Retailing, 91(2), 217-234.

Watson, R. T., Pitt, L. F., Berthon, P., \& Zinkhan, G. M. (2002). U-commerce: expanding the universe of marketing. Journal of the Academy of Marketing Science, 30(4), 333-347.

Weinberg, P., \& Gottwald, W. (1982). Impulsive consumer buying as a result of emotions. Journal of Business research, 10(1), 43-57.

Weun, S., Jones, M. A., \& Beatty, S. E. (1998). Development and validation of the impulse buying tendency scale. Psychological reports, 82(3c), 1123-1133.

Wolfinbarger, M., \& Gilly, M. C. (2001). Shopping online for freedom, control, and fun. California Management Review, 43(2), 34-55.

Workman, L. (2010). The essential structure of compulsive buying: A phenomenological inquiry (Doctoral dissertation, UTAH STATE UNIVERSITY).

Yang, K., \& Kim, H. Y. (2012). Mobile shopping motivation: an application of multiple discriminant analysis. International Journal of Retail \& Distribution Management, 40(10), 778789. 


\section{Acknowledgements}

The authors would like to thank the support provided by the Ministry of Economy, Industry and Competitiveness (Research Projects ECO2012-36275 and ECO2014-53060-R). First author is also grateful for the FPU training program of the University of Burgos. 
Table 1 . Reliability and validity of variables.

Impulsiveness ( $\alpha=.8164, \mathrm{CR}=.8898, \mathrm{AVE}=.7295)$

I often make unplanned clothing purchases.

0.901

5.808

I like to purchase clothes on a whim.

0.847

4.684

I don't think twice before buying clothes.

0.810

4.094

Need for Touch $(\alpha=.8491, \mathrm{CR}=.8977, \mathrm{AVE}=.6876)$

I feel more comfortable purchasing a product after physically

0.856

42.133

examining it.

If I can't touch a product in the store, I am reluctant to purchase it.

0.758

I feel more confident making a purchase after touching the product.

0.869

There are many products I would only buy if I could handle them

0.827

28.925

before purchase. 
Table 2. Channel use at each stage of the decision-making process.

\begin{tabular}{lcc}
\hline Decision-Making stages & ONLINE & MOBILE \\
\hline Search for information & $78.69 \%$ & $21.31 \%$ \\
Evaluating alternatives & $81.42 \%$ & $18.58 \%$ \\
Purchasing & $82.78 \%$ & $12.22 \%$ \\
Payment & $85.90 \%$ & $14.10 \%$ \\
Returns & $85.71 \%$ & $14.29 \%$ \\
Feedback & $83.11 \%$ & $16.89 \%$ \\
\hline
\end{tabular}


Table 3. Online and mobile use in the omnichannel process.

\begin{tabular}{lcc}
\hline Frequency & Online & Mobile \\
\hline 1 (not often) & $22 \%$ & $59 \%$ \\
2 & $20 \%$ & $16 \%$ \\
3 & $28 \%$ & $16 \%$ \\
4 & $21 \%$ & $6 \%$ \\
5 (very often) & $10 \%$ & $3 \%$ \\
\hline
\end{tabular}


Table 4. ANOVA results on mobile onmichannel frequency according to impulsiveness

\begin{tabular}{lllllll}
\hline & Source of variance & Sum of squares & $\mathrm{df}$ & Mean square & $\mathrm{F}$ & $\mathrm{p}$ \\
\hline Mobile & Between groups & 8.048 & 1 & 8.048 & 8.875 & 0.003 \\
omnichannel & Intra-group & 255.736 & 282 & 0.907 & & \\
frequency & Total & 263.784 & 283 & & & \\
& & & & & & \\
\hline
\end{tabular}


Table 5. ANOVA results on online onmichannel frequency according to NFT

\begin{tabular}{lllllll}
\hline & Source of variance & Sum of squares & $\mathrm{df}$ & Mean square & $\mathrm{F}$ & $\mathrm{p}$ \\
\hline $\begin{array}{l}\text { Online } \\
\text { omnichannel } \\
\text { frequency }\end{array}$ & Between groups & 11.268 & 1 & 11.268 & 17.973 & 0.000 \\
& Intra-group & 176.790 & 282 & 0.627 & & \\
& Total & 188.057 & 283 & & & \\
\hline
\end{tabular}


Table 6. ANOVA results on frequency of channel use according to impulsiveness and NFT

\begin{tabular}{lccccc}
\hline Source & Sum of Squares & $\mathrm{df}$ & Mean Square & $\mathrm{F}$ & Sig. \\
\hline Impulsiveness & $1.611^{*}$ & 1 & 1.611 & 5.257 & 0.023 \\
$\mathrm{NFT}$ & $6.135^{*}$ & 1 & 6.135 & 20.023 & 0.000 \\
Impulsiveness * NFT & 0.539 & 1 & 0.539 & 1.758 & 0.186 \\
Error & 85.798 & 280 & 0.306 & & \\
Total & 163.625 & 284 & & & \\
Corrected Total & 94.611 & 283 & & & \\
*p<0.05 & & & & &
\end{tabular}

$*_{p}<0.05$ 
Table 7. Multiple linear regression analysis results for frequency of channel use (mobile vs. online).

\begin{tabular}{lccccc}
\hline & $\mathbf{B}$ & Standard error & $\boldsymbol{\beta}$ & $\mathbf{t}$ & $\mathbf{p}$ \\
\hline Constant & -0.038 & 0.190 & & -0.203 & .839 \\
\hline Impulsiveness & -0.067 & 0.032 & $-0.116^{*}$ & -2.067 & 0.040 \\
\hline NFT & 0.168 & 0.032 & $0.291^{*}$ & 5.214 & 0.000 \\
\hline Age & 0.189 & 0.066 & $0.159^{*}$ & 2.843 & 0.005
\end{tabular}

$R=0.365 R^{2}=0.134 F=14.388(p<0.001) .{ }^{*} p<0.05$. 